Quim. Nova, Vol. 35, No. 7, 1294-1298, 2012

\title{
SELF-CONDENSATION OF $N$-( $N$-PROPYL)BUTANIMINE: NMR AND MASS SPECTRAL ANALYSES AND INVESTIGATION BY THEORETICAL CALCULATION
}

\author{
Rozângela Magalhães Manfrini, Flávia Rodrigues Teixeira, Dorila Piló-Veloso e Antônio Flávio de Carvalho Alcântara* \\ Departamento de Química, Instituto de Ciências Exatas, Universidade Federal de Minas Gerais, CP 702, 31270-901 Belo Horizonte \\ - MG, Brasil \\ David Lee Nelson \\ Departamento de Alimentos, Faculdade de Farmácia, Universidade Federal de Minas Gerais, 31270-901 Belo Horizonte - MG, Brasil \\ Ezequias Pessoa de Siqueira \\ Centro de Pesquisas René Rachou - FIOCRUZ, Av. Augusto de Lima, 1715, 30190-002 Belo Horizonte - MG, Brasil
}

Recebido em 26/4/11; aceito em 23/2/12; publicado na web em 25/6/12

\begin{abstract}
The stability of $N$-propylbutanimine (1) was investigated under different experimental conditions. The acid-catalyzed selfcondensation that produced the $E$-enimine (4) and $Z$-inimine (5) was studied by experimental analyses and theoretical calculations. Since the calculations for the energy of $\mathbf{5}$ indicated that it had a lower energy than $\mathbf{4}$, yet $\mathbf{4}$ was the principal product, the selfcondensation of 1 must be kinetically controlled.
\end{abstract}

Keywords: imine-enamine tautomerism; self-condensation of aldimines; DFT calculations.

\section{INTRODUCTION}

Compounds containing the imino group $(-\mathrm{C}=\mathrm{N}-)$ are usually called Schiff bases. ${ }^{1}$ Aliphatic aldimines, contrary to their aromatic counterparts, ${ }^{2}$ are reported to be usually unstable and susceptible to self-condensation or polymerization under different reaction conditions. ${ }^{3}$ However, aldimines can be stored for long periods under anhydrous conditions in an oxygen-free atmosphere. ${ }^{4}$

The formation of imines may lack efficiency because of their low stability. ${ }^{5}$ The instability of aliphatic aldimines in acidic medium has been attributed to polymerization of the carbinolamine intermediate formed in the reaction of aliphatic aldehydes with primary aliphatic amines. The low yields of aldimines have also been attributed to polymerization of the aldehyde substrate under acidic conditions. This polymerization competes with the formation of aldimines. ${ }^{6}$ Aldimines are normally less reactive electrophiles than the corresponding aldehydes. ${ }^{7}$ It has been demonstrated that the aldimines are stable under certain experimental conditions in which imine-enamine tautomerism is not favored. The tautomeric equilibrium is normally shifted toward the imine form ${ }^{8}$ except when the enamines result from the condensation of aldehydes with disubstituted amines. ${ }^{9}$ Low temperatures and active nucleophiles have been used to prevent the decomposition of imines in acidic media. ${ }^{6}$

Although the properties and reactivities of the aliphatic aldimines are well-known, the structure of the decomposition products were not described in detail in the literature until the early $1990 \mathrm{~s} .{ }^{10} \mathrm{In}$ fact, unidentified products were reported during the formation of imines using titanium tetrachloride as the catalyst. ${ }^{11}$ The literature also reports that unidentified products may be obtained during the synthesis of aldimines that bear alpha hydrogen atoms for the imino group. ${ }^{12}$ Although aromatic aldimines without an alpha hydrogen are stable in acidic medium, ${ }^{13}$ the presence of a methylene group between the ring and the imino group resulted in significant alterations in the ultraviolet spectrum, ${ }^{14}$ and unidentified decomposition products have been produced under these conditions. ${ }^{15}$

Few studies have been performed to characterize the products

*e-mail: aalcantara@zeus.qui.ufmg.br formed from self-condensation of imines in acidic medium. ${ }^{16}$ Imines undergo Mannich-type reactions in the presence of a catalytic amount of metallic complexes, ${ }^{17}$ and it has been suggested that these reactions occur under free radical conditions. ${ }^{18}$ The condensation of $\mathrm{N}$-unsubstituted aromatic aldimines yields trimeric products, ${ }^{19}$ while aldimines obtained from aliphatic aldehydes and primary amines provide polyenimines. ${ }^{20}$ Dimeric products named enimines $(\alpha, \beta$-unsaturated imines) were identified among the products obtained from the reaction of $\mathrm{N}$-alkylaldimines. ${ }^{21}$ There is some experimental evidence suggesting that the mechanism of dimerization catalyzed by samarium complexes occurs through the homo-condensation of imines to furnish enimines in which the $E$-isomers predominate. ${ }^{22}$ Enimines are also obtained from reactions between imines and alkynes catalyzed by gold complexes. ${ }^{23}$ Another method of obtaining enimines involves the reaction between amines and $\alpha, \beta$-unsaturated aldehydes or ketones, but this method furnishes low yields of enimines. ${ }^{24}$ When self-condensation products are identified in the literature, their configurations tend not to be specified. ${ }^{25}$ In those cases where configuration had been specified, only the $E$-isomer was mentioned. ${ }^{26}$

In view of the scarcity of information about the structure of the condensation products obtained from aldimines in acidic medium, an alternative and simple method by which enimines are formed by self-condensation of aldimines without catalysis by metal complexes is described in this work. A self-condensation mechanism was proposed with $N$-ethylbutylimine (1) as the starting material (Scheme 1). Moreover, the nucleophilic attack of the enamine tautomer (2) on an imine was proposed as the first step of the reaction to furnish an aminoimine intermediate (3). This intermediate underwent deamination to yield the corresponding $\alpha, \beta$-unsaturated imines $-E$ - (4) and Z-enimine (5) - with different configurations for the substituents on the terminal $\mathrm{sp}^{2}$ carbon, as shown in Scheme 1 . The present study was mainly based on NMR (1D and 2D) and mass spectral analyses, followed by DFT theoretical investigations.

\section{RESULTS AND DISCUSSION}

The GC chromatogram of the distilled product exhibited peaks at $\mathrm{RT}=9.880$ and $10.165 \mathrm{~min}$, respectively, with a mass spectrum 

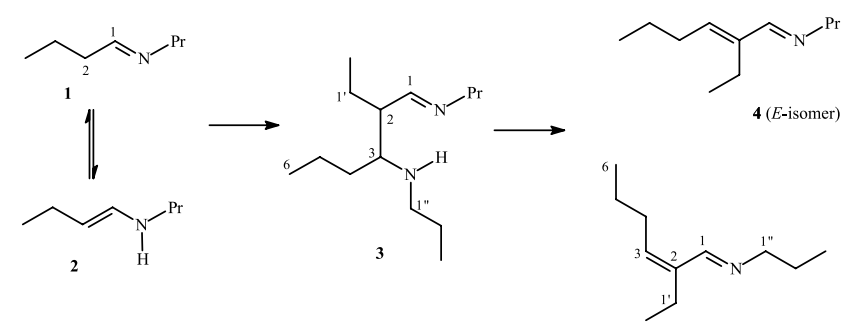

5 (Z-isomer)

Scheme 1. Chemical structure of aldimine (1), enamine (2), aminoimino intermediate (3), E-enimine (4), and Z-enimine (5) products obtained from the self-condensation of $N$-propylbutanimine

characteristic of both enimine isomers (4 and 5). The peak at $\mathrm{m} / \mathrm{z}, 167$ in the mass spectrum was attributed to the molecular ion. The peak at $\mathrm{m} / \mathrm{z}, 138$ was attributed to the loss of an ethyl radical. The base peak at $m / z, 124$ corresponds to the loss of a propyl radical.

The ${ }^{1} \mathrm{H}$ and ${ }^{13} \mathrm{C}$ NMR spectra of the distilled product indicated the presence of two different groups of signals. The high-intensity signals in the 2D NMR experimental data were first analyzed as follows. The hydrogen signal at $\delta_{\mathrm{H}} 7.67(\mathrm{H}-1)$ showed an HSQC correlation with the carbon signal at $\delta_{\mathrm{C}} 163.7(\mathrm{C}-1)$ and $\mathrm{HMBC}$ correlations with carbon signals at $\delta_{\mathrm{C}} 141.9(\mathrm{C}-2), 139.9(\mathrm{C}-3), 63.0(\mathrm{C}-1$ "), and 18.5 (C-1'). The hydrogen signal at $\delta_{\mathrm{H}} 5.70(\mathrm{H}-3)$ presented an HSQC correlation with the carbon signal at $\delta_{\mathrm{C}} 139.9$ (C-3) and HMBC correlations with carbon signals at $\delta_{\mathrm{C}} 163.7(\mathrm{C}-1), 141.9(\mathrm{C}-2), 29.8$ (C-4), 22.1 (C-5), and $18.5\left(\mathrm{C}-1^{\prime}\right)$. The hydrogen signal at $\delta_{\mathrm{H}} 3.38$ (H-1") showed an HSQC correlation with the carbon signal at $\delta_{\mathrm{C}} 63.0$ (C-1") and HMBC correlations with carbon signals at $\delta_{\mathrm{C}} 163.7$ (C-1), 23.5 (C-2"), and 11.0 (C-3"). The hydrogen signal at $\delta_{\mathrm{H}} 2.38(\mathrm{H}-1$ ') presented an HSQC correlation with the carbon signal at $\delta_{\mathrm{C}} 18.5(\mathrm{C}$ $\left.1^{\prime}\right)$ and HMBC correlations with carbon signals at $\delta_{\mathrm{C}} 163.7(\mathrm{C}-1)$, $141.9(\mathrm{C}-2), 139.9(\mathrm{C}-3)$, and $13.6\left(\mathrm{C}-2^{\prime}\right)$. The hydrogen signal at $\delta_{\mathrm{H}}$ $2.20(\mathrm{H}-4)$ correlated with the carbon signal at $\delta_{\mathrm{C}} 29.8(\mathrm{C}-1)$ in the HSQC contour map and with carbon signals at $\delta_{\mathrm{C}} 141.9$ (C-2), 139.9 (C-3), 22.1 (C-5), and 13.8 (C-6) in the HMBC contour map. In the COSY analysis, the hydrogen signal at $\delta_{\mathrm{H}} 5.70(\mathrm{H}-3)$ showed correlations with the signal at $\delta_{\mathrm{H}} 2.20(\mathrm{H}-4)$; the hydrogen signal at $\delta_{\mathrm{H}} 1.48$ $(\mathrm{H}-5)$ presented correlations with signals at $\delta_{\mathrm{H}} 2.20(\mathrm{H}-4)$ and 0.94 (H-6); the hydrogen signal at $\delta_{\mathrm{H}} 1.61$ (H-2") showed correlations with signals at $\delta_{\mathrm{H}} 3.38(\mathrm{H}-1$ ") and $0.87(\mathrm{H}-3$ "); and the hydrogen signal at $\delta_{\mathrm{H}} 2.38\left(\mathrm{H}-1^{\prime}\right)$ showed a correlation with the signal at $\delta_{\mathrm{H}} 1.04(\mathrm{H}-2$ ') These NMR data are in agreement with the corresponding data of an $N$-propyl-2-ethylhex-2-enimine. The configuration was determined to be that of the $E$-isomer 4 because of the NOESY correlation of the signal at $\delta_{\mathrm{H}} 7.67(\mathrm{H}-1)$ with the signal at $\delta_{\mathrm{H}} 5.70(\mathrm{H}-3)$.

The low-intensity signals in the 2D NMR data showed a correlation pattern (COSY, HSQC, HMBC) similar to that observed for the $E$-isomer (4). This low-intensity pattern was assigned to the $Z$-isomer (5). The hydrogen signal at $\delta_{\mathrm{H}} 8.27$, attributed to $\mathrm{H}-1$ of the $Z$-isomer $\mathbf{5}$, is more highly deshielded than that of the same hydrogen in $4\left(\delta_{\mathrm{H}} 7.67 ; \Delta \delta_{\mathrm{H}}=\delta_{\mathrm{H}-1}\right.$ of $\mathbf{5}-\delta_{\mathrm{H}-1}$ of $\left.\mathbf{4}=0.60 \mathrm{ppm}\right)$. The calculated hydrogen chemical shift difference between the corresponding $\mathrm{H}-1$ of 4 and $\mathbf{5}$ is in accord with the experimental data, i.e. $\Delta \sigma_{\mathrm{H}}=\sigma_{\mathrm{H}-1}$ of $\mathbf{5}-$ $\sigma_{\mathrm{H}-1}$ of $\mathbf{4}=0.87$ and $1.00 \mathrm{ppm}$ by BLYP/6-31G* and B3LYP/6-31G* calculations, respectively. In addition, other comparisons between experimental and calculated chemical shifts confirm the structural characterization of $\mathbf{4}$ and $\mathbf{5}$. Thus, $\Delta \delta_{\mathrm{H}-3}=0.08 \mathrm{ppm}$ and $\Delta \sigma_{\mathrm{H}-3}=$ $0.13 \mathrm{ppm}$ (by BLYP/6-31G* calculations) and $\Delta \sigma_{\mathrm{H}-3}=0.31 \mathrm{ppm}$ (by B3LYP/6-31G* calculations) for the respective hydrogen chemical shifts, while the values for the corresponding carbon chemical shifts were $\Delta \delta_{\mathrm{C}-3}=-4.40 \mathrm{ppm}$ and $\Delta \sigma_{\mathrm{C}-3}=-8.58 \mathrm{ppm}$ (by BLYP/6-31G* calculations) and $\Delta \sigma_{\mathrm{C}-3}=-4.39 \mathrm{ppm}$ (by B3LYP/6-31G* calculations), respectively. On the other hand, the fact that $\mathrm{C}-1$ of $\mathbf{5}$ is more highly shielded $\left(\delta_{\mathrm{C}} 157.9\right)$ than $\mathrm{C}-1$ of $\mathbf{4}\left(\delta_{\mathrm{C}} 163.7\right)$ is in accordance with the $\gamma$ interaction in the $Z$-isomer.

The formation of $\mathbf{4}$ and $\mathbf{5}$ may be explained by deamination of 3 (Scheme 1). In turn, the latter may be formed by condensation of 1 with 2 (Scheme 1). Enamines have higher energies than the corresponding imines and, for this reason, are not experimentally observed. ${ }^{27}$ The first step in the formation of an enimine occurs through nucleophilic attack of the enamine on the carbon of the imino group. ${ }^{28}$ Similar to the case of enaminones, the reactivity of enamines towards electrophilic reactants is localized on $\mathrm{C}-2 .{ }^{29} \mathrm{In}$ fact, $N$-t-butyl-2,2-dichlorobutanimine, which has no hydrogen bound to the carbon alpha for the imino group, was obtained via the reaction between $N$ - $t$-butylbutanimine and $N$-chlorosuccinimide. ${ }^{30}$ The NMR signal at $\delta_{\mathrm{H}} 7.64$, attributed to the imino hydrogen of $N$ - $t$-butyl-2,2dichlorobutanimine, remained unaltered for two months following the addition of a catalytic quantity of butanoic acid.

The mass spectrum of the distilled product did not exhibit a peak at $\mathrm{m} / z, 226$ that might be attributed to the molecular ion of the iminoamine intermediate 3 . In addition, the ${ }^{1} \mathrm{H}$ and ${ }^{13} \mathrm{C}$ NMR spectra and DEPT $135^{\circ}$ subspectrum of the distilled product and residue did not show signals that might be attributed to $\mathbf{3}$.

Deamination of $\mathbf{3}$ was investigated by theoretical calculations using the BLYP/6-31G* level. A lower energy was obtained for the $Z$-isomer than for the $E$-isomer $\left(\Delta E=E_{5}-E_{4}=2.22 \mathrm{kcal} / \mathrm{mol}\right.$ by BLYP/6-31G* and $3.06 \mathrm{kcal} / \mathrm{mol}$ by B3LYP/6-31G*), suggesting that the formation of $\mathbf{5}$ is thermodynamically controlled. In spite of this fact, the $E$-isomer $\mathbf{4}$ was the principal product obtained.

Only two configurations were considered for aminoimine 3 the pro- $E$-enimine (C-2 and C-3 presenting $S$ and $R$ configurations, respectively) and the pro-Z-enimine (both C-2 and C-3 having the $S$ configuration). Other possibilities for the configurations at $\mathrm{C}-2$ and $\mathrm{C}-3$ correspond to the enantiomers of these structures. The Newman projections of the pro-E-enimine and pro-Z-enimine are shown in Scheme 2. BLYP/6-31G* geometry optimizations indicated a lower energy for the pro-Z-enimine than for the pro-E-enimine, but the energy difference is small $(\Delta E=0.58 \mathrm{kcal} / \mathrm{mol})$ and does not explain the higher proportion of $\mathbf{4}$ than $\mathbf{5}$ in the distilled product.

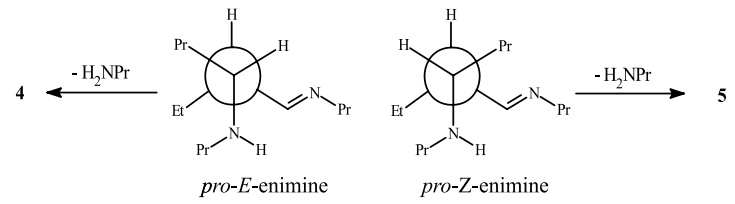

Scheme 2. Newman projections of the pro-E-enimine and pro-Z-enimine configurations of the aminoimine intermediate 3

The transition states for pro-E-enimine and pro-Z-enimine formation were investigated using the BLYP/6-31G* level and furnished the ET-pro-E and ET-pro-Z optimized geometries, respectively. The theoretical calculations indicated a lower energy for ET-pro-E than for ET-pro- $Z(\Delta E=0.74 \mathrm{kcal} / \mathrm{mol})$. Although the energy difference is small, the high-intensity signals in the NMR experiments for the distilled product must certainly be related to 4. Because of this small energy difference, the formation of $\mathbf{4}$ must be kinetically controlled. In fact, the self-condensations of $\mathbf{1}$ in the presence of a catalytic quantity of butanoic acid in DMSO were performed at different temperatures during a $24 \mathrm{~h}$ period. The effect of temperature on the $E / Z$ isomer ratio was verified for reactions at 25,80 , and $180{ }^{\circ} \mathrm{C}$. An increase in temperature lead to a higher proportion of $Z$-isomer $\left(0.15,0.22\right.$, and 0.41 , respectively). ${ }^{31}$ The $E / Z$ isomer ratio in the reaction mixture was determined by integration of the imino hydrogen signals registered in the ${ }^{1} \mathrm{H}$ NMR spectrum 
$\left(\delta_{\mathrm{H}-1} 8.27\right.$ for 5 and $\delta_{\mathrm{H}-1} 7.67$ for $\left.\mathbf{4}\right)$. As a consequence, the decrease in relative intensity of the signal at $\delta_{\mathrm{H}-1} 7.67(\mathrm{H}-1$ of 4) may also be a result of decomposition of this enimine.

On the other hand, the mass spectrum of the residue from the distillation exhibited a peak at $\mathrm{m} / \mathrm{z}, 280$ that may be attributed to the molecular ion of the iminoenamine 6 (Scheme 3). This compound was formed by condensation of enamine $\mathbf{2}$ with enimine $\mathbf{4}$ or $\mathbf{5}$. In fact, the ${ }^{1} \mathrm{H}$ NMR spectrum of the residue presented a low-intensity doublet at $\delta_{\mathrm{H}} 7.50(J=6.0 \mathrm{~Hz})$ and a singlet at $\delta_{\mathrm{H}} 5.68$ that may be attributed to $\mathrm{H}-5$ and $\mathrm{H}-1$ of 6 , respectively. Moreover, the ${ }^{13} \mathrm{C}$ NMR spectrum and DEPT $135^{\circ}$ subspectrum of the residue also had lowintensity signals at $\delta_{\mathrm{C}} 167.2,131.2,113.6,63.9$, and 59.9 that, based on carbon chemical shift calculations, were attributed to C-5, C-1, C-2, C-1', and C-1", respectively, of 6 .

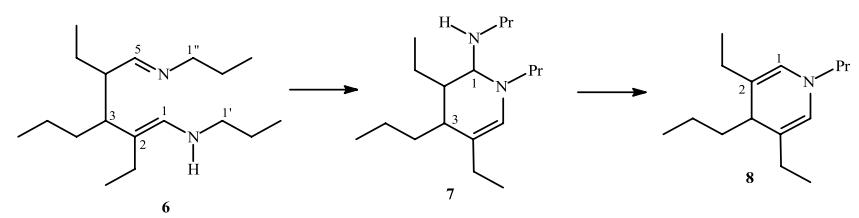

Scheme 3. Chemical structures proposed after MS and NMR analyses of the residue obtained from self-condensation of imine 1

The GC/MS chromatogram of the residue also contained a peak at $\mathrm{m} / \mathrm{z} 221$ in the mass spectrum that may be attributed to the molecular ion of the dienamine $\mathbf{8}$. This by-product can be formed from cyclization of $\mathbf{6}$, as is shown in Scheme 3. The ${ }^{13} \mathrm{C}$ NMR spectrum and DEPT $135^{\circ}$ subspectrum of this residue also present low-intensity signals at $\delta_{\mathrm{C}} 126.6$ and 108.3 that, based on calculated carbon chemical shifts, may be attributed to C-1/C-5 and C-2/C-4, respectively, of 7 .

\section{EXPERIMENTAL}

\section{General}

IR spectra were recorded on an FTIR Perkin Elmer Spectrum 200 spectrometer in $\mathrm{KBr}$ pellets. The ${ }^{1} \mathrm{H}$ and ${ }^{13} \mathrm{C}$ NMR spectra at 400.129 and $100.613 \mathrm{MHz}$, respectively, as well as the ${ }^{1} \mathrm{H}-{ }^{1} \mathrm{H}$ COSY $\left({ }^{2} J_{\mathrm{H}, \mathrm{H}}\right.$ and $\left.{ }^{3} J_{\mathrm{H}, \mathrm{H}}\right),{ }^{1} \mathrm{H}-{ }^{1} \mathrm{H}$ NOESY $\left(J_{\mathrm{H}, \mathrm{H}}\right.$ long distance $),{ }^{1} \mathrm{H}-{ }^{13} \mathrm{C}$ HMBC $\left({ }^{\mathrm{n}} J_{\mathrm{H}, \mathrm{C}}, \mathrm{n}=2,3\right.$, and 4$),{ }^{1} \mathrm{H}-{ }^{13} \mathrm{C} \mathrm{HMQC}\left({ }^{1} J_{\mathrm{H}, \mathrm{C}}\right)$, and ${ }^{1} \mathrm{H}-{ }^{13} \mathrm{C} \operatorname{HSQC}\left({ }^{1} J_{\mathrm{H}, \mathrm{C}}\right)$ experiments were performed on a Brüker DRX400 AVANCE spectrometer, using $\mathrm{CDCl}_{3}$ as the solvent, with direct or inverse probes and a field gradient. The chemical shifts were registered in ppm $(\delta)$ relative to TMS as the internal standard. The coupling constants $(J)$ were registered in Hertz. Experiments were performed using the pulse sequence and programs provided by the manufacturer. ${ }^{1} \mathrm{H}$ and ${ }^{13} \mathrm{C}$ NMR spectra were acquired under standard conditions by using a direct detection $5-\mathrm{mm}{ }^{1} \mathrm{H} /{ }^{13} \mathrm{C}$ dual probe. Standard pulse sequences were used for 2D homonuclear and heteronuclear shift correlation techniques by employing a multinuclear inverse detection 5-mm probe with a field gradient at the $z$-axis. Three delays for the evolution of long-range coupling $\left[1 /\left({ }^{\mathrm{n}} J_{\mathrm{C}-\mathrm{H}}\right), 65,125\right.$, and $\left.130 \mathrm{~ms}\right]$ were used for ${ }^{1} \mathrm{H}-{ }^{13} \mathrm{C}$ HMBC experiments. For the ${ }^{1} \mathrm{H}-{ }^{1} \mathrm{H}$ NOESY experiment, two mixing times ( 350 and $700 \mathrm{~ms}$ ) were pre-optimized by a specific Brüker computer program.

Mass spectra (MS) by electron impact at $70 \mathrm{eV}$ were obtained on a Shimadzu QP 5050-A gas chromatograph-mass spectrometer (GC/MS) (JP). Chromatographic separations were performed on a PTE $^{\text {TM }}$-5 (Supelco, USA.) column (30 m x $0.25 \mathrm{~mm}$ i.d. x $0.25 \mu \mathrm{m}$ film) with helium as the mobile phase at a flow rate of $56.6 \mathrm{~mL} / \mathrm{min}$. The carrier gas pressure was $120 \mathrm{kPa}$. One microliter of sample solution $(10 \mu \mathrm{g} / 100 \mu \mathrm{L}$ of hexane) was injected using a 1:26 split; the injector temperature was $240^{\circ} \mathrm{C}$. The column temperature was programmed with an initial temperature of $60^{\circ} \mathrm{C}$ and heated to $150^{\circ} \mathrm{C}$ at a rate of $5{ }^{\circ} \mathrm{C} / \mathrm{min}$, followed by heating to $250^{\circ} \mathrm{C}$ at a rate of $20^{\circ} \mathrm{C} /$ min. Retention time (RT) is given in minutes. The mass range was 40 to $500 \mathrm{~m} / \mathrm{z}$ at a rate of five scans per second. Data acquisition and handling was performed with CLASS 5000 Shimadzu software. Raw data files were analyzed by the automated mass deconvolution and identification system (AMDIS) software, version 2.1, supplied by the National Institute of Standards and Technology (NIST, USA). The identification of the components was achieved using the Nist Mass Spectral Search Program for the NIST/EPA/NIH Mass Spectral Library, version 2002, upgraded to 2006 (NIST, USA).

\section{Procedure for the synthesis of $N$-propylbutanimine (1)}

A solution of $0.20 \mathrm{~mol}$ of butanal in $50 \mathrm{~mL}$ of dichloromethane was added to a solution of $0.20 \mathrm{~mol}$ of propylamine in $100 \mathrm{~mL}$ of dichloromethane in a three-neck, round-bottom flask equipped with an addition funnel, Dean-Stark apparatus, and condenser with a calcium chloride drying tube, over a 15 -min period while stirring in an ice bath. The mixture was heated under reflux for $4 \mathrm{~h}$ and dried over magnesium sulfate. The solvent was removed at atmospheric pressure, and the product was distilled under reduced pressure to afford $\mathbf{1}\left(92 \%\right.$ yield) as a yellow oil. ${ }^{32}$

$N$-propylbutanimine $(\mathbf{1})$ : bp $28{ }^{\circ} \mathrm{C} / 26 \mathrm{mmHg}$; IR $\left(\mathrm{KBr} ; \mathrm{cm}^{-1}\right) \mathrm{v}$ 2990-2820, 1670, 1460, 1210, 1150, and 1100; ${ }^{1} \mathrm{H}$ NMR (400 MHz; $\left.\mathrm{CDCl}_{3} ; \mathrm{ppm}\right) \delta_{\mathrm{H}} 7.60(\mathrm{t}, J=4.4 \mathrm{~Hz} ; \mathrm{H}-1), 3.30(\mathrm{t}, J=6.8 \mathrm{~Hz} ; \mathrm{H}-1$ ' $)$, 2.14-2.17 (m; H-2), 1.62-1.51 (m; H-3 and H-2'), 0.96-0.93 (t, $J=$ $7.6 \mathrm{~Hz} ; \mathrm{H}-4)$, and $0.90-0.86\left(\mathrm{t}, J=7.2 \mathrm{~Hz} ; \mathrm{H}-3^{\prime}\right) ;{ }^{13} \mathrm{C}$ NMR $(100$ $\left.\mathrm{MHz} ; \mathrm{CDCl}_{3} ; \mathrm{ppm}\right) \delta_{\mathrm{C}} 161.7$ (C-1), $61.6\left(\mathrm{C}^{-1}\right.$ '), 35.9 (C-2), 22.4 (C-2'), 17.9 (C-3), 11.8 (C-4), and 9.5 (C-3').

\section{Procedure for the synthesis of $(E)$ - and $(Z)-N$-propyl-2- ethylhex-2-enimines}

Butanoic acid $(0.02 \mathrm{~mol})$ in $50 \mathrm{~mL}$ of pentane was added dropwise over a period of $15 \mathrm{~min}$ to a stirred solution of $0.20 \mathrm{~mol}$ of aldimine 1 in $100 \mathrm{~mL}$ of pentane in an ice bath. The reaction mixture was stirred at room temperature for $36 \mathrm{~h}$ and then dried over magnesium sulphate. The pentane was removed under atmospheric pressure, and the products were distilled under reduced pressure to furnish the distilled product (59.3\% yield of enimines $\mathbf{4}$ and $\mathbf{5}$ ) and a nonvolatile residue. The $E / Z$ isomer ratio (0.89:0.11) in the distilled product was calculated by integration of the imino hydrogen signals registered in the ${ }^{1} \mathrm{H}$ NMR spectrum. The physical data for the $Z$-isomer are only partially described here because of the predominance of the $E$-isomer in the distilled product.

(E)-N-Propyl-2-ethylhex-2-enimine (4): IR $\left(\mathrm{KBr} ; \mathrm{cm}^{-1}\right) \vee 2950$ 2850, 1675, 1665, 1645, 1625, 1460, 1450, 1380, 1320, 1220, 1150, 1085,1065 , and $970 ;{ }^{1} \mathrm{H} \mathrm{NMR}\left(400 \mathrm{MHz} ; \mathrm{CDCl}_{3} ; \mathrm{ppm}\right) \delta_{\mathrm{H}} 7.67(\mathrm{~s}$; H-1), 5.70 (t, $J=7.6 \mathrm{~Hz} ; \mathrm{H}-3$ ), 3.38 (t, $J=6.8 \mathrm{~Hz}$; H-1"), 2.38 (q, $J$ $=7.6 \mathrm{~Hz} ; \mathrm{H}-1$ '), 2.20 (q, $J=7.6 \mathrm{~Hz} ; \mathrm{H}-4), 1.61$ (sextet, $J=7.6 \mathrm{~Hz}$; H-2”), 1.48 (sextet, $J=7.6 \mathrm{~Hz}$; H-5), 1.04 (t, $J=7.6 \mathrm{~Hz}$; H-2'), 0.94 (t, $J=7.6 \mathrm{~Hz}$; H-6), and 0.87 (t, $J=7.6 \mathrm{~Hz} ; \mathrm{H}-3$ ") $) ;{ }^{13} \mathrm{C}$ NMR $(100$ $\left.\mathrm{MHz} ; \mathrm{CDCl}_{3} ; \mathrm{ppm}\right) \delta_{\mathrm{C}} 163.7$ (C-1), 141.9 (C-2), 139.9 (C-3), 63.0 (C-1”), 29.8 (C-4), 23.5 (C-2”), 22.1 (C-5), 18.5 (C-1'), 13.8 (C-6), 13.6 (C-2'), and $11.0(\mathrm{C}-3$ '”); GC $R T=10.165 \mathrm{~min}, \mathrm{MS}(\mathrm{EI} ; 70 \mathrm{eV})$ $\mathrm{m} / z 167\left[\mathrm{M}^{+}, 138,124\right.$ (base peak), 109, 96, 82, 81, 80, 70, 69, 68, $67,56,55$, and 53.

(Z)- $N$-Propyl-2-ethylhex-2-enimine (5): ${ }^{1} \mathrm{H}$ NMR (400 MHz; $\left.\mathrm{CDCl}_{3} ; \mathrm{ppm}\right) \delta_{\mathrm{H}} 8.27(\mathrm{~s} ; \mathrm{H}-1), 5.78(\mathrm{t}, J=7.6 \mathrm{~Hz} ; \mathrm{H}-3)$, and $3.43(\mathrm{t}$, $J=6.8 \mathrm{~Hz} ; \mathrm{H}-1 ") ;{ }^{13} \mathrm{C} \mathrm{NMR}\left(100 \mathrm{MHz} ; \mathrm{CDCl}_{3} ; \mathrm{ppm}\right) \delta_{\mathrm{C}} 157.9(\mathrm{C}-1)$, 139.2 (C-2), 135.7 (C-3), 63.5 (C-1"), 28.5 (C-4), 25.4 (C-2”), 22.8 (C-5), 18.9 (C-1'), 13.8 (C-6), 13.6 (C-2'), and 11.0 (C-3"). 


\section{Theoretical method}

Theoretical studies were performed using the Gaussian03 software package. ${ }^{33}$ Spatial arrangements determined from NMR data were used as initial models for geometry optimizations of $\mathbf{4}$ and $\mathbf{5}$. DFT geometry optimizations were performed using the geometries previously obtained by the PM3 semi-empirical method. ${ }^{34}$ The BLYP and B3LYP/6-31G* functionals with standard Pople's split valence 6-31G* base set were used for DFT calculations. ${ }^{35}$ The optimized geometries were characterized as true minima on the potential energy surface (PES) when all harmonic frequencies were real. The BLYP/6-31G* and B3LYP/6-31G* calculations have been efficiently employed to investigate chemical properties of other organic compounds containing carbon-to-nitrogen bonds. ${ }^{36}$ This fact justifies the use of these calculations for amine and imine derivatives.

The electron-nuclear energies (E) were calculated by DFT methods. BLYP/6-31G* and B3LYP/6-31G* optimized geometries were used in carbon chemical shift calculations at the same level of theory. Carbon chemical shifts $\left(\sigma_{\mathrm{C}}\right)$ were calculated relative to the corresponding value for tetramethylsilane using BLYP/6-31G* $\left(\sigma_{\mathrm{H}}\right.$ 32.14 and $\left.\sigma_{\mathrm{C}} 186.02\right)$ and B3LYP/6-31G* $\left(\sigma_{\mathrm{H}} 32.18\right.$ and $\left.\sigma_{\mathrm{C}} 189.68\right)$ calculations.

Correlations between $\sigma_{\mathrm{C}}$ values and experimental carbon chemical shifts $\left(\delta_{\mathrm{C}}\right)$ were obtained using the Origin ${ }^{\mathrm{TM}}$ Standard 7.5 software package. The $\sigma_{\mathrm{C}}$ and $\delta_{\mathrm{C}}$ values were plotted on $x$ - and $y$-axes, respectively. Correlation curves were given as linear fits with correlation coefficients $\left(\mathrm{R}^{2}\right)$ furnished by the program.

\section{CONCLUSION}

In conclusion, an efficient method for the specific synthesis of $\alpha, \beta$-unsaturated imines without catalysis by metal complexes was developed. Aliphatic aldimines bearing alpha hydrogen are not stable in acidic medium, and the imine-enimine tautomerism is favored. The nucleophilic attack of the enamine tautomer on the corresponding imine furnished aminoimine intermediates with two different configurations (pro-E-enimine and pro-Z-enimine). BLYP/6-31G* calculations showed that the transition state for the pro-E-enimine had a lower energy than the transition state for the pro-Z-inimine, but the intermediate pro-Z-enimine had a lower energy than the pro-E-enimine. Considering that the $Z$-enimine had a lower energy than the $E$-enimine while the latter was the principal product, the self-condensation of $\mathrm{N}$-propylbutanimine must be kinetically controlled. An increase in temperature produced a higher proportion of the $Z$-isomer.

\section{ACKNOWLEDGEMENTS}

The authors thank the Conselho Nacional de Desenvolvimento Científico e Tecnológico (CNPq), the Fundação Coordenação de Aperfeiçoamento de Pessoal de Nível Superior (CAPES), and the Fundação de Amparo à Pesquisa do Estado de Minas Gerais (FAPEMIG) for financial support.

\section{REFERENCES AND NOTES}

1. Tidwell, T. T.; Angew. Chem., Int. Ed. 2008, 47, 1016.

2. Kimpe, N.; Verhe, R.; Schamp, N.; Synth.Commun. 1975, 5, 269; Textier-Boullet, F.; Synth. Commun. 1985, 6, 679; Musick, B.; J. Org. Chem. 1990, 55, 910; Leardini, R.; Nanni, D.; Santori, M.; Zanardi, G.; Tetrahedron 1992, 48, 3961; Hattori, K.; Yamamoto, H.; Tetrahedron 1993, 49, 1749; Mladenova, M.; Bellassoued, M.; Synth. Commun. 1993, 23 , 725; Zhao, D.; Moore, J. S.; J. Org. Chem. 2002, 67, 3548; Sánchez, C.
O.; Alvarado, F.; Bustos, C. J.; Schott, E.; Gatica, N.; Valdebenito, K.; Polymer Bull. 2007, 59, 319.

3. Tiollais, R.; Bull. Soc. Chim. Fr. 1947, 14, 716; Nagata, W.; Hayase, Y.; Tetrahedron Lett. 1968, 4359; Wittig, G.; Hesse, A.; Organic Synth., Coll. 1970, 50, 66; Neumann, R.; Levin, M.; J. Org. Chem. 1991, 56, 5707; Suh, J.; Min, D. W.; J. Org. Chem. 1991, 56, 5710; Sevilla, J. M.; Blazquez, M.; Dominguez, M.; Garcia-Blanco, F.; J. Chem. Soc., Perkin Trans. 1992, 2, 921; Costero, A. M.; Rodrigues, S.; Tetrahedron Lett. 1992, 33, 623; Pierre, J. L.; Gagnaire, G.; Chautemps, P.; Tetrahedron Lett. 1992, 33, 217; Yuliang, W.; Aiquiao, M.; Yaozhong, J.; Synth. Commun. 1992, 22, 265; Sollandie-Cavallo, A.; Bencheqroun, M.; Bonne, F.; Synth. Commun. 1993, 23, 1683; Manabe, K.; Oyamada, K. S.; Kobayashi, S.; J. Org. Chem. 1999, 64, 8054; Kobayashi, S.; Ueno, M.; Suzuki, R.; Ishitani, H.; Kim, H. S.; Wataya, Y.; J. Org. Chem. 1999, 64, 6833; Zhou, P.; Chen, B.-C.; Davis, F. A.; Tetrahedron 2004, 60, 8003; Schenkel, L. B.; Ellman, J. A.; Org. Lett. 2004, 6, 3621; Trincado, M.; Ellman, J. A.; Angew. Chem., Int. Ed. 2008, 120, 5705.

4. Weingarten, H.; Chupp, J. P.; White, W. A.; J. Org. Chem. 1967, 32, 3246; Texier-Boullet, F.; Synth. Commun. 1985, 6, 679; Musicki, B.; J. Org. Chem. 1990, 55, 910; Nielsen, A. T.; Nissan, R. A.; Vanderah, D. J.; Coon, C. L.; Gilardi, R. D.; George, C. F.; Flippen-Anderson, J.; J. Org. Chem. 1990, 55, 1459; Larkin, D. R.; J. Org. Chem. 1990, 55, 1563; Yuliang, W.; Aiqiao, M.; Yaozhong, J.; Synth. Commun. 1992, 22, 265; Ramasseul, R.; Tavares, M.; Marchon, J. C.; J. Chem. Res. (S) 1992, 104; Schedler, D. J.; Godfrey, A. G.; Ganem, B.; Tetrahedron Lett. 1993, 34, 5035 .

5. Ddkimpe, N.; Yao, Z.-P.; Boeykens, M.; Nagy, M.; Tetrahedron Lett. 1990, 31, 2771.

6. Kallen, R. G.; Jencks, W. P.; J. Biol. Chem. 1966, 241, 5864; Kretzschmann, H.; Meier, H.; Tetrahedron Lett. 1991, 32, 5059; Kardon, F.; Mörtl, M.; Knausz, D.; Tetrahedron Lett. 2000, 41, 8937.

7. Lautens, M.; Tayama, E.; Nguyen, D.; Tetrahedron Lett. 2004, 45, 5131.

8. Yi-Fan, H.; Xin, L.; Chin. J. Struct. Chem. 2008, 27, 547.

9. Minière S.; Cintrat, S. C.; J. Org. Chem. 2001, 66, 7385.

10. Jencks, W.; Progr. Phys. Org. Chem. 1964, 2, 63; Patai, S.; The Chemistry of the Carbon-Nitrogen Double Bond, Wiley: London, 1970; Dyke, S. F.; The Chemistry of Enamines, Cambridge Univ. Press: London, 1973; Bjorgo, J.; Boyd, D. R.; Watson, C. G.; Jennings, W. B.; J. Chem. Soc., Perkin Trans. II 1974, 757; Smith, P. A. S.; Dang, C. V.; J. Org. Chem. 1976, 41, 2013; Buchanan, G. W.; Dawson, B. A.; Can. J. Chem. 1977, 55, 1437; Tennant, G.; Comprehensive Organic Chemistry - The Synthesis and Reactions of Organic Compounds, Pergamon Press: Oxford, 1979; March, J.; Advanced Organic Chemistry - Reactions, Mechanisms and Structure, Wiley: New York, 1985; Sola, R.; Commeyras, A.; J. Chem. Res. 1992, 180.

11. Jennings, W. B.; Lovely, C. J.; Tetrahedron Lett. 1988, 29, 3725.

12. Grigg, R.; Montgomery, J.; Somasunderama, A.; Tetrahedron 1992, 48, 10431.

13. Nielsen, A. T.; Atkins, R. L.; Moore, D. W.; Scott, R.; Mallory, D.; LaBerger, J. M.; J. Org. Chem. 1973, 38, 3288; Forlani, L.; Marianucci, E.; Todesco, P. E.; J. Chem. Res. 1984, 126; Rossi, M. H.; Atachissini, A. S.; Amaral, L. J.; J. Org. Chem. 1990, 55, 1300.

14. Csaszar, J.; Acta Phys. Chem., Szeged. Hung. 1981, 25, 47; Chiang, Y.; Kresge, A. J.; Walsh, P. A.; J. Org. Chem. 1990, 55, 1309; Onys'ko, P. P.; Kim, T. V.; Kiseleva, E. I.; Sinitsa, A. D.; Tetrahedron Lett. 1992, 33, 691.

15. Nielson, A. T.; Nissan, R. A.; Vanderah, D. J.; Coon, C. L.; Gilardi, R. D.; George, C. F.; Flippen-Anderson, J.; J. Org. Chem. 1990, 55, 1459.

16. Campbell, K. N.; Sommers, A. H.; Campbell, B. K.; J. Am. Chem. Soc. 1944, 66, 82 .

17. Ueno, M.; Ishitani, H.; Kopbayashi, S.; Org. Lett. 2002, 4, 3395.

18. Novak, B. M.; Cafmeyer, J. T.; J. Am. Chem. Soc. 2001, 123, 11083.

19. Nielsen, A. T.; Atkins, R. L.; Dipol, J.; Moore, D. W.; J. Org. Chem. 1974, 39, 1349. 
20. Layer, R. W.; Chem. Rev. 1963, 63, 489.

21. Kelly, S. E.; Vanderplas, B. C.; J. Org. Chem. 1991, 56, 1325.

22. Shiraishi, H.; Kawasaki, Y.; Sakaguchi, S.; Nishiyama, Y.; Ishii, Y.; Tetrahedron Lett. 1996, 37, 7291.

23. Suárez-Pantiga, S.; Rubio, E.; Alvarez-Rúa, C.; González, J. M.; Org. Lett. 2009, 11, 13

24. Denmark, S. E.; Venkatraman, S.; J. Org. Chem. 2006, 71, 1668.

25. Levai, L.; Bozsing, D.; Benko, P.; Lax, G.; Mikite, G.; Tompe, P.; Nagy, A.; Furdyga, E.; Synth. Commun. 1992, 22, 47; Polop, F.; Lazar, L.; Bernath, G.; Sillampaa, R.; Pihlaja, K.; Tetrahedron 1993, 49, 2115.

26. Kimpe, N.; Staboeva, E.; Verhe, R.; Schamp, N.; Synthesis 1988, 8, 587; Gaudemar, M.; Bellassoued, M.; Tetrahedron Lett. 1990, 31, 349.

27. Nishitani, T.; Shiraishi, H.; Sakaguchi, S.; Ishii, Y.; Tetrahedron Lett. 2000, 41, 3389.

28. Abdel-Khalik, M. M.; Elnagdi, M. H.; Synth. Commun. 2002, 32, 159.

29. Kobayashi, S.; Ishitani, H.; Yamashita, Y.; Ueno, M.; Shimizu, H.; Tetrahedron 2001, 57, 861.

30. To a solution of $N$-propylbutanimine $(0.22 \mathrm{~mol})$ in $150 \mathrm{~mL}$ of pentane was added $N$-chlorosuccinimide $(0.40 \mathrm{~mol})$ in an ice bath. The reaction mixture was stirred at room temperature for $24 \mathrm{~h}$ and filtered. Aliquots of the reaction mixture were analyzed by ${ }^{1} \mathrm{H}$ NMR before and after addiction of $0.02 \mathrm{~mol}$ of butanoic acid.

31. Butanoic acid $(0.02 \mathrm{~mol})$ in $50 \mathrm{~mL}$ of DMSO was added dropwise over a period of $15 \mathrm{~min}$ to a stirred solution of $0.20 \mathrm{~mol}$ of aldimine 1 in 50 $\mathrm{mL}$ of DMSO at room temperature. Aliquots of the reaction mixture were stirred at different temperatures $\left(25,80\right.$, and $\left.180^{\circ} \mathrm{C}\right)$ for $36 \mathrm{~h}$ and analyzed by ${ }^{1} \mathrm{H}$ NMR.

32. Alcântara, A. F. C.; Piló-Veloso, D.; Nelson, D. L.; J. Braz. Chem. Soc. 1996, 7, 225.

33. Gaussian 03, Revision B.04; Frisch, M. J.; Trucks, G. W.; Schlegel, H. B.; Scuseria, G. E.; Robb, M. A.; Cheeseman, J. R.; Montgomery, J. A.,
Jr.; Vreven, T.; Kudin, K. N.; Burant, J. C.; Millam, J. M.; Iyengar, S. S.; Tomasi, J.; Barone, V.; Mennucci, B.; Cossi, M.; Scalmani, G.; Rega, N.; Petersson, G. A.; Nakatsuji, H.; Hada, M.; Ehara, M.; Toyota, K.; Fukuda, R.; Hasegawa, J.; Ishida, M.; Nakajima, T.; Honda, Y.; Kitao, O.; Nakai, H.; Klene, M.; Li, X.; Knox, J. E.; Hratchian, H. P.; Cross, J. B.; Adamo, C.; Jaramillo, J.; Gomperts, R.; Stratmann, R. E.; Yazyev, O.; Austin, A. J.; Cammi, R.; Pomelli, C.; Ochterski, J. W.; Ayala, P. Y.; Morokuma, K.; Voth, G. A.; Salvador, P.; Dannenberg, J. J.; Zakrzewski, V. G.; Dapprich, S.; Daniels, A. D.; Strain, M. C.; Farkas, O.; Malick, D. K.; Rabuck, A. D.; Raghavachari, K.; Foresman, J. B.; Ortiz, J. V.; Cui, Q.; Baboul, A. G.; Clifford, S.; Cioslowski, J.; Stefanov, B. B.; Liu, G.; Liashenko, A.; Piskorz, P.; Komaromi, I.; Martin, R. L.; Fox, D. J.; Keith, T.; Al-Laham, M. A.; Peng, C. Y.; Nanayakkara, A.; Challacombe, M.; Gill, P. M. W.; Johnson, B.; Chen ,W.; Wong, M. W.; Gonzalez, C.; Pople, J. A.; Gaussian, Inc., Pittsburgh PA, 2003.

34. Dewar, M. J. S.; Zoebish, E. G.; Healy, E. F.; Stewart, J. J. P.; J. Am. Chem. Soc. 1985, 107, 902.

35. Ditchfield, R.; Hehre, W. J.; Pople, J. A.; J. Chem. Phys. 1971, 54, 724; Hehre, W. J.; Ditchfield, R.; Pople, J. A.; J. Chem. Phys. 1972, 56, 2257; Hariharan, P. C.; Pople, J. A.; Theor. Chim. Acta 1973, 28, 213; Hariharan, P. C.; Pople, J. A.; Mol Phys 1974, 27, 209; Gordon, M. S.; Chem. Phys. Lett. 1980, 76, 163.

36. Alcântara, A. F. C.; Teixeira, A. F.; Piló-Veloso, D.; Silva, I. E.; Almeida, W. B.; Quim. Nova 2004, 27, 371; De Abreu, H. A.; Lago, I. A. S.; Souza, G. P.; Piló-Veloso, D.; Duarte, H. A.; Alcântara, A. F. C.; Org. Biomol. Chem. 2008, 6, 2713; Vieira, F. T.; Lima, G. M.; Wardell, J. L.; Wardell, S. M. S. V.; Krambrock, K.; Alcântara, A. F. C.; J. Organomet. Chem. 2008, 693, 1986; Santos, F. J. L.; Alcântara, A. F. C.; FerreiraAlves, D. L.; Piló-Veloso, D.; Struct. Chem. 2008, 19, 625; Oliveira, P. M.; Pacheco, A. G.; Alves, R. B.; Piló-Veloso, D.; Raslan D. S.; Alcântara, A. F. C.; Open Nat. Prod. J. 2009, $2,1$. 